Hoenig, M. Jirsa und E. Fabian, Čas. Lěk. česk., im Druck. 12. Fabian, E., L. Kučerová, A. Śtork und J. Śponarovi, Plzcňský sbornik, im Druck. - 13. Sprrzer, J. J., IIIrd Internat. Conf. on Biochemical Problems of Lipids (Brüssel, 1956); Klaase der Wetenschapen, 1957 Belgie. - 14. Novík, M., J. Lipid. Res. 6, 456 (1965). - 15. Engelberg, H., Amer. J. Cardiol. 14, 8 (1964). - 16. Therkelsen, A. J., Scand. J. Clin. Laborat.
Invest. 9, 156 (1957). - 17. Zemplényr, T., Cas. lěk. česk. 97, 1230 (1958). - 18. LeBreton, E., Ch. Frayssinet und P. May, Bull. Acad. suisse sc. méd. 13, 229 (1957). - 19. Frayssinet, C. und P. MAY IIIrd Internat. Conf. on Biochemical Problems of Lipids (Brüssel, 1956), Klaase der Wetenschapen. 1957 Belgie. - 20. Max, P., C. R. Acad. Sci. Paris 245, 2551 (1957).

Dr. L. Kučerová

I. Medizinische Klinik der Karls-Universität Prag 2, U nemocnice 2

\title{
Determination of citric acid in urine and in serum
}

\author{
By I. Antener, L. Vuataz, A. Bruschi and M. Kaeser \\ From the Nestle Research Laboratories (Director Dr. R. H. Egli) Vevey, Switzerland
}

(Eingegangen am 26. Januar 19.66)

\begin{abstract}
A method is described for the determination of citric acid in the routine clinical investigation of urine and serum. It is based on a combination of the methods of GEY, LANE and CHEN. The method has been used for several years and has been completed by a statistical analysis.
\end{abstract}

Es wird die Beschreibung einer Zitronensäurebestimmungsmethode im Harn und Serum, die sich gut zu Reihenuntersuchungen in der Klinik eignet, gegeben. Sie beruht auf der Kombination der Methoden von GEY undLANE und CHEN. Während mehrerer Jahre wurde diese Methode angewendet und durch eine Statistik ergänzt.

Recent progress in clinical chemical methods has shown the importance of citric acid in the different metabolic pathways. Its storage and release is influenced by vitamin $\mathrm{D}$ and parathormone, and it is a metabolite of the Krebs cycle. Citric acid is also a bone component. Moreover, the secretion and tubular reabsorption of renal citric acid are two problems which remain unsolved. Determinations of serum and urinary citric acid are thus not only of interest in the different bone diseases, but also in certain kidney and liver diseases.

The clinical laboratory therefore needs a method for the determination of citric acid in urine and in serum, which is precise, rapid and not too complicated. This paper describes such a method which we have used in our laboratory. Our six years of experience have shown it to be capable of fulfilling all the necessary requirements of the clinical laboratory. Above all, we would like to emphasize its accuracy which permits, for example, the differentiation of certain diseases by analysis of the citric acid levels in serum.

We have found many methods for the determination of citric acid in the literature, most of them based on the conversion of citric acid into pentabromacetone $(\mathrm{Pba})$, with various modifications for its oxidation and extraction (2-12). We have retained the methods of GEY, and LANE and CHEN. After trying both, we decided that a judicious combination of the two would permit us to shorten the time required for the determination without sacrificing its sensitivity. We therefore kept LANE et al's sequence of oxidation at low temperature and the subsequent reduction of the excess permanganate by hydrogen peroxide. We then substituted GEY's technique for extraction with petroleum ether, elimination of traces of acid, and formation of the $\mathrm{Pba}$-thiourea-borax complex.
Thus the combination of the two methods permits us to shorten the time required for the determination without affecting the accuracy of the results. By adopting GEx's method of extraction, we have eliminated certain inherent errors of the NaI-ethanol extraction, for example the influence of light, temperature and the possible contamination of the NaI-Pba-ethanol mixture by acids, which would have to be eliminated by washing with water and the phosphate buffer. Furthermore, the $\mathrm{Pba}$-thioureaborax complex is not affected by the presence of $\beta$-hydroxybutyric acid, acetone and succinic acid, even in pathological quantities. The $\mathrm{Pba}-\mathrm{NaI}$-ethanol reaction is sensitive to the aforementioned compounds, as well as to aspartic acid.

\section{Method}

\section{Principle}

Citric acid is converted into pentabromacetone ( $\mathrm{Pba})$ in acidic solution and at low temperature by a reagent consisting of potassium bromide and potassium permanganate. The excess potassium permanganate is reduced by hydrogen peroxide. The $\mathrm{Pba}$ formed is extracted with light petroleum, the extract is washed, and the $\mathrm{Pba}$ re-extracted with a solution of sodium borate thiourea. The resulting complex has an absorption maximum at $450 \mathrm{~m} \mu$.

\section{Reagents}

10\% Trichloroacetic Acid: $10 \mathrm{~g}$ trichloroacetic acid (p. a.) Grade $\mathrm{A}+90 \mathrm{~m} l$ distilled water.

Sulfuric Acid $9 \mathrm{~N}: 252 \mathrm{ml}$ conc. $\mathrm{H}_{2} \mathrm{SO}_{4}$ (density 1,84, Grade A) to $1 l$ with distilled water.

Standard Citric Acid Solution: Dissolve $100 \mathrm{mg}$ anhydrous citric acid or $109,8 \mathrm{mg}$ citric acid $1 \mathrm{H}_{2} \mathrm{O}$ in $10 \mathrm{ml} 9 \mathrm{~N} \mathrm{H}_{2} \mathrm{SO}_{4}$ and dilute to. 
$100 \mathrm{~m} l$ with distilled water. It contains $1 \mathrm{~m} l=1000 \mu \mathrm{g}$ citric acid. Store under refrigeration. For the standard curve, dilute so that $1 \mathrm{ml}$ contains $25,50,75$ and $100 \mu \mathrm{g}$.

Sulfuric-Metaphosphoric Acid: Dissolve $5 \mathrm{mg}$ metaphosphoric acid in $9 \mathrm{~N} \mathrm{H}_{2} \mathrm{SO}_{4}$ without heating and dilute to $50 \mathrm{ml}$.

Potassiumbromide-Potassiumpermanganate: Weigh $5,95 \mathrm{~g} \mathrm{KBr}$ into a $100 \mathrm{ml}$ volumetric flask and make up to volume with a saturated $\mathrm{KMnO}_{4}$ solution. (Saturated $\mathrm{KMnO}_{4}$ : Dissolve $5,95 \mathrm{~g}$ in $100 \mathrm{ml}$ of boiled distilled water). This solution can be stored in glass- stoppered brown bottles for over 6 months in the dark.

$\mathrm{H}_{2} \mathrm{O}_{2} 3 \%$ : Dilute analytical $30 \%$ reagent $1: 10$ with distilled water; prepare daily.

Petroleum ether: Shake petroleum ether (boiling point $80^{\circ}-100^{\circ}$ ) with activated charcoal; filter and distill.

Borate-tliourea solution: Dissolve $4 \mathrm{~g}$ Borax $\left(\mathrm{Na}_{2} \mathrm{~B}_{4} \mathrm{O}_{7} \cdot 10 \mathrm{H}_{2} \mathrm{O}\right)$ (Grade A) in $100 \mathrm{ml}$ distilled watër. Dissolve $4 \mathrm{~g}$ thiourea in $100 \mathrm{ml}$ of this solution. This reagent should be freshly made for each set of detcrminations.

\section{Procedure}

Standard curve: Pipette $1 \mathrm{ml}$ standard dilutions ( $25 \mu \mathrm{g}$, $50 \mu \mathrm{g}, 75 \mu \mathrm{g}$ and $100 \mu \mathrm{g}$ ) into $50 \mathrm{ml}$ Erlenmeyer flasks. Add $1 \mathrm{~m} l \mathrm{H}_{3} \mathrm{PO}_{3}-\mathrm{H}_{2} \mathrm{SO}_{4}$ reagent. Cool the flask in an ice bath. Add $2 \mathrm{~m} l \mathrm{KBr}-\mathrm{KMnO}_{4}$ reagent, mix, and allow to stand in the ice bath for 10 minutes. Add $\mathrm{H}_{2} \mathrm{O}_{2}$, dropwise with constant mixing, until decolorisation. It is advisable to wait 1 minute between the addition of each drop towards the end of the decolorisation. Carefully avoid any excess.

Washing: Transfer the contents of the flask into a $50 \mathrm{ml}$ separating funnel with a ground-glass stopper. Rinse the flask with about $5 \mathrm{~m} l$ distilled water, then add $5 \mathrm{~m} l$ cooled petroleum ether to the funnel and shake for 1 minute (avoid emulsions!). The neck and stopper of the funnel should be carefully rinsed with petroleum ether. (Use a Pasteur-pipette). When the layers are well separated, discard the water, add $10 \mathrm{~m} l$ of distilled water, and shake for 30 seconds. Repeat as above and eliminate the water as completely as possible.

Extraction: Add $5 \mathrm{ml}$ Borax-thiourea reagent (at room temperature) and shake vigorously for 5 minutes. Decant the lower phase into a tube and centrifuge at $2000 \mathrm{rpm}$ for 5 minutes. Read the extinction against unreacted Borax-thiourea solution at $450 \mathrm{~m} \mu$ using $1 \mathrm{~cm}$ light path cell in the Beckman spectrophotometer Mod. "B", "DB" or "DU". There should be a time lapse of no greater than 20 minutes between the extraction of the sample with the Borax-thiourea solution and the reading with the spectrophotometer. Once a standard curve has been established, it is sufficient to repeat only one point on the curve for each series of determinations.

Urine without albumin: Run each sample in duplicate. If the urine is cloudy, centrifuge. Dilution: $1 \mathrm{~m} l$ in $10 \mathrm{~m} l$ or $2 \mathrm{ml}$ or more in $10 \mathrm{~m} /$ distilled water - according to the concentration of citric acid in the sample $-.1 \mathrm{ml}$ of the diluted sample $+1 \mathrm{ml} \mathrm{H}_{2} \mathrm{O}+0,29 \mathrm{~m} l$ conc. $\mathrm{H}_{2} \mathrm{SO}_{4}$. Boil 10 minutes in a water bath, cool. Add $1 \mathrm{~m} l$ $\mathrm{H}_{2} \mathrm{SO}_{4}-\mathrm{H}_{3} \mathrm{PO}_{3}$ reagent and proceed as described for the standard curve.

Urine with albumin: Shake equal volumes of urine and $10 \%$ TCA. Centrifuge. Pipette $1 \mathrm{~m} l$ of the supernatant, add $1 \mathrm{~m} l \mathrm{H}_{2} \mathrm{O}+0,29 \mathrm{~m} l$ conc. $\mathrm{H}_{2} \mathrm{SO}_{4}$ and proceed as above.

Serum: Deproteinize $1 \mathrm{~m} l, 2 \mathrm{ml}$ or, if possible, more serum with an equal volume of $10 \% \mathrm{TCA}$, centrifuge and use $1 \mathrm{~m} l$ supernatant $+1 \mathrm{~m} l \quad \mathrm{H}_{2} \mathrm{O}+0,29 \mathrm{~m} l$ conc. $\mathrm{H}_{2} \mathrm{SO}_{4}$. Proceed as above.

\section{Important points}

1. Samples are heated with $\mathrm{H}_{2} \mathrm{SO}_{4}$ to eliminate a nonidentified substance which obscures the Pba-thioureaborax complex at $450 \mathrm{~m} \mu$.

2. The reduction of the excess oxidant with $\mathrm{H}_{2} \mathrm{O}_{2}$ in an ice bath must be done slowly and carefully. An excess of $\mathrm{H}_{2} \mathrm{O}_{2}$ causes a loss of $\mathrm{Pba}$.

3. The time lapse between the extraction of the $\mathrm{Pba}$ complex with the thiourea-borax reagent and its reading with the spectrophotometer must not be longer than 25-30 minutes. We have discovered a diminution of $4 \%$ of the extinction for time lapses greater than 35 minutes. 4. The extinction of the sample should be between 0.1 and 0.45 .

5. A point on the standard curve should be determined with each series of determinations.

6. Determinations should be made on fresh samples, but if this is not possible the 24-hour urine should be divided and stored in small plastic bottles which are kept in the freezer. If a determination must be repeated, we suggest using a new sample which has never been defrosted.

\section{Statistical Part}

We start by assuming orthogonality. The reference straight line is established from $n$ observations equally distributed between the 4 levels of X: 25, 50, 75 and $100 \mu \mathrm{g}$ of citric acid. These levels are assigned the coded values $Z=-3,-1,1,3$. The relation between $X$ and $Z$ is

$$
\mathrm{X}=12.5 \mathrm{Z}+62.5
$$

The first step is the analysis of variance which shows whether the regression $y=a+b z$ is valid. At the same time, this analysis gives an estimate of the variance of the experimental error. - If the regression is valid, the equation

$$
y=a+b z
$$

may be used under the form

$$
\mathrm{Z}=\frac{\overline{\mathrm{y}}_{0}-\mathrm{a}}{\mathrm{b}}
$$

where $\bar{y}_{0}$ is a response corresponding to an unknown value of $Z$. Needless to say, the new determinations must be carried out under the same conditions as those under which the regression line was determined. Finally, $\mathrm{X}$ is calculated from (1).

The second step consists of the calculation of the confidence interval attached to $Z$. This may be effected by FinLLER's method (1). The notation given in the reference will be used. - In our problem, the value of $g$ is so small that it may be distegarded. Therefore, we can use the simplified expression

$$
Z_{L}, Z_{U}=Z \pm \frac{t s}{b}\left(V_{11}+Z^{2} V_{22}\right)^{1 / 2}
$$

where $Z$ is given by (3)

$t$ is StudenT's $t$

$\mathrm{S}$ is the standard deviation of the experimental error

$$
V_{11}=\frac{1}{S^{2}} \operatorname{Var}\left(\bar{y}_{0}-a\right)=\frac{1}{m}+\frac{1}{n}
$$


where $m$ is the number of observations at the unknown value of $\mathrm{X}$ and $\bar{y}_{0}$ their mean

$$
\mathrm{V}_{22}=\frac{1}{\mathrm{~S}^{2}} \mathrm{Var} b=\frac{1}{\xi \mathrm{Z}_{2}}
$$

Finally, $X_{L}$ and $X_{U}$ are calculated from (1) after replacing $Z$ by $\mathrm{Z}_{\mathrm{L}}$ and $\mathrm{Z}_{\mathrm{U}}$.

\section{Numerical example}

We consider here a non-orthogonal experiment. For reasons unknown to us, unequal numbers of observations were allotted to the four levels of $\mathrm{X}$. The assistant fitted a regression line by eye and used it as reference in subsequent analysis. It was therefore necessary to proceed to the statistical analysis.

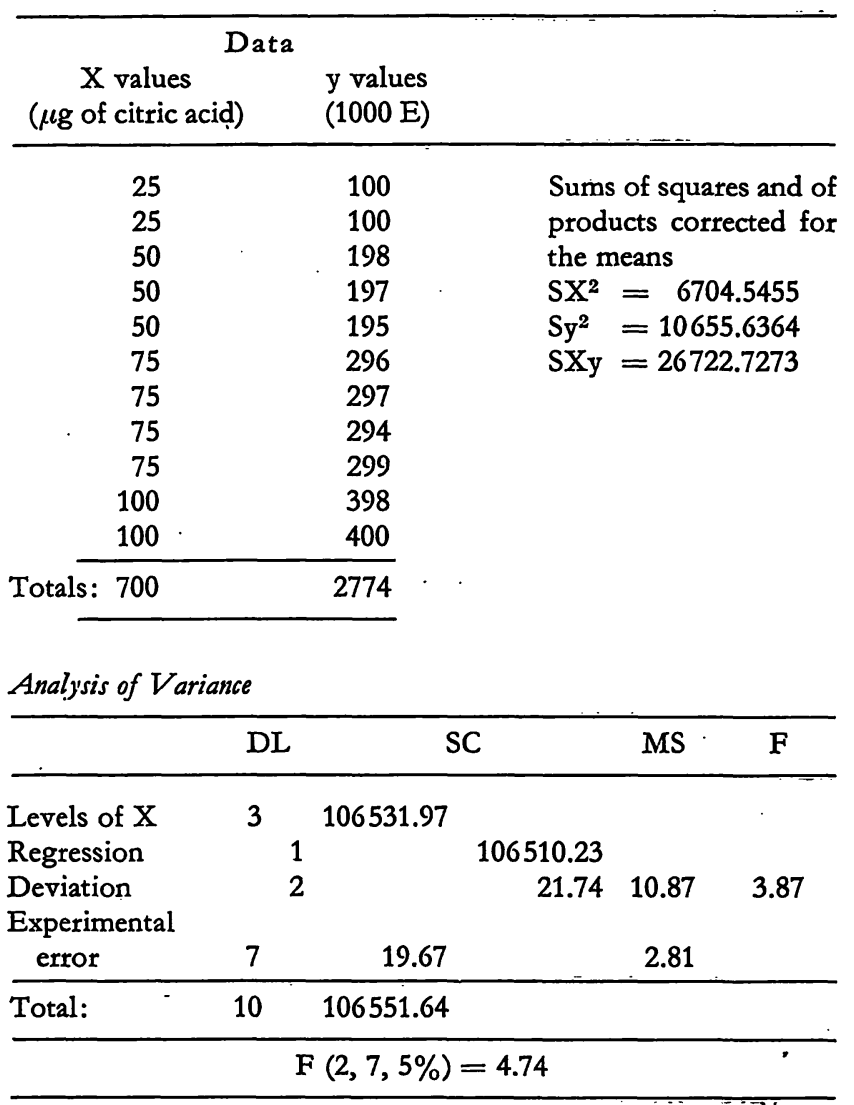

The linear regression is valid.

$$
\begin{aligned}
b & =\frac{S X y}{S X^{2}}=3.486 \\
a & =\bar{y}-b \bar{X}=-1.473 \\
y & =-1.473+3.986 X \text { and } \\
X & =\frac{\bar{y}_{0}+1.473}{3.986}
\end{aligned}
$$

where $\bar{y}_{0}$ is the average response obtained for an unknown value of $\mathbf{X}$.

\section{Confidence interval of $X$}

Owing to the lack of orthogonality, the determination of the confidence interval is a little more complicated than in the balanced case.

$$
\text { Starting from } X=\frac{\bar{y}_{0}-a}{b} \text { and }
$$

using the notation of the reference we must determine

$$
\begin{aligned}
& V_{11}=\frac{1}{S^{2}} \operatorname{Var}\left(\bar{y}_{0}-a\right)=\frac{1}{S^{2}}\left(\operatorname{Var} \bar{y}_{0}+\operatorname{Var} a\right) \\
& V_{22}=\frac{1}{S^{2}} \operatorname{Var} b \\
& \left.V_{12}=\frac{1}{S^{2}} \operatorname{Cov}\left[\left(\bar{y}_{0}-a\right), b\right)\right]=-\frac{1}{S^{2}} \operatorname{Cov}(a, b)
\end{aligned}
$$

Vat a, Var b and Cov (a, b) are given by the diagonal and nondiagonal terms of the matrix (13)

$$
\mathrm{X}^{\prime}=\left[\begin{array}{rrrrrrrrrrr}
1 & 1 & 1 & 1 & 1 & 1 & 1 & 1 & 1 & 1 & 1 \\
25 & 25 & 50 & 50 & 50 & 75 & 75 & 75 & 75 & 100 & 100
\end{array}\right]
$$

We obtain Var $a=0.694915 \mathrm{~S}^{2} ; \operatorname{Var} \mathrm{b}=0.000149 \mathrm{~S}^{2} ; \operatorname{Cov}(\mathrm{a}, \mathrm{b})$ $=0.009492 \mathrm{~S}^{2}$.

On the other hand, Var $\overline{\mathrm{y}}_{0}=\frac{\mathrm{S}^{2}}{\mathrm{~m}}$.

Thus we have $\mathrm{V}_{11}=\frac{1}{\mathrm{~m}}+0.694915 ; \quad \mathrm{V}_{22}=0.000149 ; \mathrm{V}_{12}$ $=0.009492$.

As in the orthogonal case, the value of $g$ may be distegarded. The confidence interval is given by the simplified expression:

$$
\begin{aligned}
& \mathrm{X}_{\mathrm{U}}, \mathrm{X}_{\mathrm{L}}=\mathrm{X} \pm \frac{\mathrm{ts}}{\mathrm{b}}\left(\mathrm{V}_{11}-2 \mathrm{XV}_{12}+\mathrm{X}^{2} \mathrm{~V}_{22}\right)^{1 / 3} \\
& \text { where } \dot{\mathrm{X}}=\frac{\overline{\mathrm{y}}_{0}+1.473}{3.986}
\end{aligned}
$$

$\mathrm{t}=2.365$ (STUDENT's $\mathrm{t}$ for 7 degrees of freedom; $\mathrm{S}^{2}=2.81$; $\mathrm{b}=3.986 ; \mathrm{V}_{11}, \mathrm{~V}_{22}$ and $\mathrm{V}_{12}$ are defined as above.

\section{Example}

Two determinations give

1) $\dot{\bar{y}}_{0}=108$

2) $\left.\begin{array}{l}\bar{y}_{0}=109\end{array}\right\} \bar{y}_{0}=108.5 \mathrm{~m}=2$

$$
\begin{aligned}
X & =\frac{108.5+1.473}{3.986}=27.59 \\
\mathrm{X}_{U}, \mathrm{X}_{\mathrm{L}} & =27.59 \pm 0.99 \times 0.785^{1 / 2} \\
\text { hence } \mathrm{X} & =27.59 \pm 0.88 .
\end{aligned}
$$

We wish to thank Miss SMrTH (Vevey) for the English translation.

\section{References}

1. FrnNey, D. T., Statistical methods in biological assay, p. 28, Griffin, (1952). - 2. BeutLER, E. and M. K. J JeH, J. Laborat. Clin. Med., 54, 125 S. Louis. (1959) - 3: Erringer, R. H., L. R. Goldbaum and L. H. SMIth jr., J. biol. Chemistry 199, 531 (1952). -4. GEY, K. F., Int. Z. Vitaminforsch. 25, 21 (1953). - 5. LANE, K. and P. CHEN jr., Rapid determination of citric acid in biological fluids. University of Rochester (1960). - 6. Lrchrwrrz, A., D. Hroco, R. Parlier et S. DE SEze, Presse méd. Paris 69, 51 (1961). - 7. McArdle, B., Biochem. J. 60, 647. (1955). - 8.
Natelson, S., J. B. Pincus and Lưgovoy, J. biol. Chemistry 175, 745 (1948). - 9. TöRök, J., P. TuraY and Z. Kovacs, Mschr. Kinderhk. 110, 477 (1962). - 10. Pucher, G. W., C. C. Sherman. and H. B. VICkerY, J. biol. Chemistry 113, 235 (1936). - 11. TAYLOR, T. G., Biochem. J. 54, 48 (1953). - 12. Weri-Malherbe, H. and A. D. Bone, Biochem. J. 45, 377 (1949). - 13. KEMThorN, O., The Design and Analysis of Experiments. J. Wiley \& Sons, New York 1952.
Dr. Ilse Antener
Laboratoire de Recherche
Nestlé, Vevey (Schweiz) 